\title{
Landslide Susceptibility Assessment Based on Geological Data and Remote Sensing Processed Data Using Bi-Variate Statistical Model and GIS: A Case Study on Rangamati District, Bangladesh
}

\section{Bibi Hafsa}

Jahangirnagar University Faculty of Social Science

Md. Sharafat Chowdhury ( $\square$ sharafat.44@geography-juniv.edu.bd)

Jahangirnagar University Faculty of Social Science https://orcid.org/0000-0001-5046-1671

Md. Naimur Rahman

Jahangirnagar University Faculty of Social Science

\section{Research}

Keywords: Geology, Remote Sensing, GIS, Bi-variate statistical approach, Landslide Susceptibility

Posted Date: August 27th, 2020

DOI: https://doi.org/10.21203/rs.3.rs-63452/v1

License: (c) (i) This work is licensed under a Creative Commons Attribution 4.0 International License. Read Full License 


\section{Abstract}

Landslide is a major hazard all over the world and a very frequent phenomenon in Southeast Asian mountainous terrain. It has become a frequent phenomenon in the hilly regions of Bangladesh and the Rangamati district is the worst victims. This study aims to identify the landslide susceptible area of Rangamati district according to geological and satellite image processed data of the previously occurred landslide. Geological map of Rangamati District, Landsat 8 OLI images of October-2019 and SRTM images were used for landslide factor data mining. In present study Surface geology, Distance from fault line, Slope Angle, Slope Aspect, NDVI, BSI and NDCl are considered as the major factors related to landslide occurrence. Effects of the selected factors were calculated by using bivariate statistical approach (frequency ratio method) to examine the correlation between landslide occurrence and the influencing factors. Results of the landslide susceptibility show that surface geology and fault line has a strong correlation with landslide occurrence in Rangamati district. Analysis also shows that medium to high clay content availability with bare soil surface (no or low vegetation) that have a low slope angle ( 3 to 16 degree) are closely correlated to landslide occurrence. In the rainy season clay content saturated by heavy rainfall produce mud that flows according to very low slope cause landslide in this region. Due to geological characteristics this landslide can be defined as mud flow. Landslide susceptible map shows that the area near water bodies and lower part of hill slope are more susceptible to landslide occurrence.

\section{Introduction}

Landslides and associated slope failure phenomena (e.g. debris flows and mudslides) are a major hazard around the world (Chapagai 2011). Cited in Farahmand and AghaKouchak (2013), each year, it cause thousands of casualties and billions of dollars in damages across the world and results in 10 of deaths and over 1-2 billion USD in property damages (USGS 2006). For example in 1982-1983 millions of dollars loss occurred in USA due to several storm triggered landslide and in 1999 thousands of people died due to landslide in Vargas, Venezuela (Spiker and Gori 2003; Hong et al. 2006). Also in South and South-east Asia landslides are most widespread and frequent disaster because of climatic condition (rainfall), mountainous terrain and socioeconomic conditions (Apip et al. 2010; Chapagai, 2011).

In the hilly region of Bangladesh, especially in Chattagram region, during monsoon, landslides has become a very common natural hazard and are occurring very frequently (Alam et al 2005; Ahmed et al. 2014). On June 12, 2017 in three hilly districts of Bangladesh (Rangamati, Chattagram and Bandarban) heavy monsoon rain triggered a series of landslides and killed at least 152 people (The financial express 2017). Among them the worst hit district was Rangamati (BBC NEWS 2017). Recent landslide in this district has sparked discussions whether natural or anthropogenic causes or both were responsible for triggering devastating landslides in the hill tracts region of Bangladesh (Rahman, Mohiuddin and Hassan 1985).

The higher hill ranges in the Chattagram Hill Tracts, Chattagram and Sylhet regions are underlain by rocks of the Surma and Tipam formation (Brammer 1996; BBS 2009a, b). The composition of soil of these hilly regions is complex and the young rocks have higher contents of easily-weatherable feldspars[1]. Therefore, the soil of this hilly region is very much susceptible to the landslide risks during heavy rain carried by monsoon wind system (Sarker and Rashid 2013).

Now a day's Landsat images are easily available and are used to explore various indices and characteristics of land surface. In this study Landsat images are used to explore the topographic and lithologic condition of the study area. Different bands of remote sensing image can provide information about the chemical composition of rocks and minerals that area on the Earth's surface and not completely covered by dense vegetation (Clark et al. 2003; Clark et al. 1990).

To take any action plan for a landslide affected region it is important to know the type of land and characteristics of land slide of that region (Chapagai 2011). Since landslides generally occur in existing slide areas, it is vital to know the locations of previously occurred landslides, the size of the landslides, and their related geomorphological factors (Chen et. al. 2017). Many study conducted for assessing landslide susceptibility of Rangamati Sadar Upazila by using statistical method and GIS where satellite image derived landslide triggering data were used. The major satellite derived data used in this study are land cover and NDVI and some common morphological data such as DEM, elevation, slop, aspect plan curvature etc. (Haque et al. 2018; Khatun et al. 2018; Kafy et al. 2019; Alam et al. 2019; Begum, Islam and Hasan 2020).

Considering the above aspect, this research attempts to explore the geomorphic and geologic status of the landslide occurrence area to produce Landslide Susceptibility Map (LSM) by GIS and remote sensing based approach. At first various topographic characteristics of the study area derived from Landsat imageries. Factors responsible for landslide occurrence such as vegetation, bareness, slope angle and aspect, clay content surface geology and fault line distance are analysed to fulfill first objective of the research. These factors are related to the lithologic and geologic condition of the study area. For the second objective, correlation between landslide occurrence and the selected factors are calculated.

\section{Footnote:}

[1] Feldspars are group of rock forming minerals make up as much as $60 \%$ of the earth crust.

\section{Materials And Methods}

\section{Study Area}

Rangamati district has an area of $6116.13 \mathrm{sq} \mathrm{km}$ and is located in between $22^{\circ} 27^{\prime}$ and $23^{\circ} 44^{\prime}$ north latitudes and in between $91^{\circ} 56^{\prime}$ and $92^{\circ} 33^{\prime}$ east longitudes. The district is bounded by Tripura state of India on the north, Bandarban district on the south, Mizoram state of India and Chinpradesh of Mayanmar on the east, Khagrachhari and Chattagram districts on the west (BBS 2001; CSRRD2007; CSRRURD 2007). 


\section{Methodological Summary}

Flow chart of the broad steps followed in this research for deriving results are given in Figure 2.

\section{Data and Data Source}

Historical landslide events of Rangamati district were considered in this research (Table 1). Geological map of Bangladesh was collected from Geological Survey of Bangladesh (GSB) server (Link: http://www.gsb.gov.bd/site/view/commondoc/Geo-scientific\%20Map/-?page=3\&rows=20). Landsat-8 OLI images and SRTM elevation images of the study area were collected from USGS server (Link: https://earthexplorer.usgs.gov/). Landsat image of rainy season was collected to measure the soil condition of the study area because landslide occurs during monsoon season. Table 1 shows the historical landslide events of Rangamati district and their common cause, casualties and number of wounded people.

Table 1: Historical Landslide Events of Rangamati District

\begin{tabular}{|c|c|c|c|c|}
\hline Date & Location & Casualties & Wounded & Cause of landslide \\
\hline 1968 & Kaptai-Chondroghon road section & - & 02 & $\begin{array}{l}\text { Removal of protective } \\
\text { vegetation and heavy } \\
\text { rainfall. }\end{array}$ \\
\hline 1970 & Ghagra-Rangamati Road Section & 01 & - & $\begin{array}{l}\text { Removal of protective } \\
\text { vegetation and heavy } \\
\text { rainfall. }\end{array}$ \\
\hline 1997 & $\begin{array}{l}\text { Rangamati, Bandarban, } \\
\text { Cox's Bazar, and } \\
\text { Chattagram }\end{array}$ & 30 & 10 & Heavy rainfall \\
\hline 2017 & Vedvedi, Reserve Bazar, Juraichhari, Bilaichhari, Kawkhali & 100 & & Heavy rainfall \\
\hline 2018 & Naniarchar, Burighat, Reserve Bazar, Juraichhari & 12 & & Heavy rainfall \\
\hline 2019 & KPM, Chandraghona, & 2 & & - \\
\hline 2019 & Raikhali & 2 & 3 & Heavy rainfall \\
\hline
\end{tabular}

(Source: 1 Banglapedia [10], The Daily star, The Daily ProthomAlo, The Daily Azad, and The Daily Ittefaq, BanglaTribune, DhakaTribune.)

\section{Data Processing}

Selected factors responsible for landslide occurrence are calculated by using ArcMap 10.5 software and Microsoft Excel 2007 software. Geological map of Rangamati district is derived from Geological map of Bangladesh. Distance from fault line is calculated by using euclidean distance tool of ArcMap 10.5 . NDVI (Normalized Difference Vegetation Index), NDCI (Normalized Difference Clay Index), BSI (Bare Soil Index) indices and Slope of the study area were measured from predetermined formula (Table 2) by using ArcMap 10.5. Slope angle and slope aspect were measured from SRTM images by using ArcMap 10.5 software. Correlation of the selected factors are calculated by using Microsoft excel software.

\section{Table 2: Information of the Indices}

\begin{tabular}{|ll|}
\hline Band of Landsat8 OLI used & Formula of the indices \\
B2 $=$ Visible blue & $\mathrm{NDVI}=($ NIR-RED $) /(\mathrm{NIR}+\mathrm{RED})$ \\
$\mathrm{B} 4=$ Visible red & $\mathrm{NDCl}=$ Short wavelength infrared-1/ Short wavelength infrared-2 \\
$\mathrm{B} 5=$ Near-infrared & $\mathrm{BSI}=(\mathrm{B} 6+\mathrm{B} 4)-(\mathrm{B} 5+\mathrm{B} 2)\} /\{(\mathrm{B} 6+\mathrm{B} 4)+(\mathrm{B} 5+\mathrm{B} 2)\}$ \\
$\mathrm{B} 6=$ Short wavelength infrared-1 & \\
B7 $=$ Short wavelength infrared-2 & \\
\hline
\end{tabular}

\section{Frequency Ratio (FR) Method}

General assumption to predict landslide is that landslide occurrence is determined by landslide related factors and the future landslides will occur under the same conditions as the past landslide (Lee and Talib 2005). The Frequency Ratio method represents the possibility of the occurrence for a given characteristic (Bonham-Carter 2014). Cited in Nohai et al (2019), the FR method examines the relationship between the distribution of landslide occurrence locations and each of the factors influencing landslides and is used to reveal correlation between them (Lee and Talib 2005). FR $>1$ indicates e great proportion of landslide occurrences to the area and a high correlation and FR<1 show a weak correlation (Akgun, Dag and Bulut 2008). Equation (1) shows the FR algorithm,

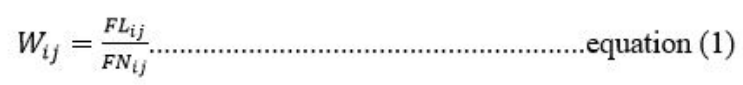


where Wij shows the FR of class i of parameter j; FLij is the frequency of occurrence of landslides for class i of parameter j; and FNij is the frequency of nonoccurrence of landslides for class i of parameter $\mathrm{j}$. Then the Probability Ratio of each factor was calculated and finally by using ArcMap 10.5 Landslide Susceptibility Map (LSM) of Rangamati district was produced.

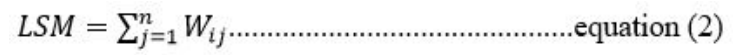

Where, Wij is the weight of class $i$ of parameter $j$, and $n$ is the number of conditioning factors.

\section{Result And Discussion}

In generally landslide occurred in relatively high elevated area. This research attempts to explore the land characteristics of previously occurred landslide area and produce a LSM according to the result. Findings show that the major surface geology that responsible for landslide occurrence is Dihing and Dupitila Formation Undivided and Boka Bil Formation. $80 \%$ landslide occurred in his two geological formations where Boka Bil formation alone is responsible for $47 \%$ landslide (Table 4 and Fig. 3). Distance from fault line has major role in landslide occurrence and $93 \%$ of the landslide occurred within a distance of 11000 meter from fault line where $33 \%$ within a distance of 5500 meter (Table 4 and Fig. 4). Twelve out of fifteen landslide event occurred where slope angle is between 3.71 and 16.85 degree and nine of them occurred where slope is below 12 degree (Fig. $6 . B$ and Tables 3 and 4 ). Fourteen landslides occurred where normalized difference clay index is ranged medium (1.33-1.44) to high (1.44-1.52) (Fig. 5.C and Tables 3 and 4). This indicates huge saturated clay content flows according to low slope that can be regarded as mudflow. Low to medium bare soil index and medium to high normalized difference vegetation index shows similar result (Fig. 5.A and 5.B and Tables 3 and 4). Though aspect plays major role in weathering material for occurring landslide, in this area it is oriented according to water body (Kaptai Lake and Karnafuli river). In Rangamati, slope aspects that have similar orientation with fault line have most correlation with landslide occurrence. So that north, northeast, south and southwest slope aspect has major correlation with landslide occurrence.

Table 3

Results of various indices in the land slide occurrence site

\begin{tabular}{|c|c|c|c|c|c|c|}
\hline Location & Year & NDVI & BSI & $\mathrm{NDCl}$ & Slope & Aspect \\
\hline Kaptai-Chondroghona main road & 1968 & $0.41-0.48$ & $-0.19--0.14$ & $1.44-1.52$ & $12.57-16.85$ & SW \\
\hline Raozan-Ghagra-Rangamati main road & 1970 & $0.27-0.41$ & $-0.19--0.14$ & $1.44-1.52$ & $21.13-25.71$ & NW \\
\hline Naniarchar & 2018 & $0.48-0.65$ & $-0.39--0.22$ & $1.44-1.52$ & $12.57-16.85$ & NNW \\
\hline KPM & 2019 & $0.27-0.41$ & $-0.19--0.14$ & $1.33-1.44$ & $25.71-31.13$ & NE \\
\hline Chandraghona & 2019 & $0.41-0.48$ & $-0.19--0.14$ & $1.33-1.44$ & $8.28-12.57$ & SW \\
\hline Raikhali union & 2019 & $0.41-0.48$ & $-0.22--0.19$ & $1.44-1.52$ & $16.85-21.14$ & NE \\
\hline Burighat & 2018 & $0.41-0.48$ & $0.22-0.19$ & $1.44-1.52$ & $3.71-8.28$ & S \\
\hline Vedvedi & 2017 & $0.27-0.41$ & $-0.19--0.14$ & $1.44-1.52$ & $8.28-12.57$ & NE \\
\hline Reserve Bazar & $2008,2017,2018$ & $0.27-0.41$ & $-0.19--0.14$ & $1.33-1.44$ & $3.71-8.28$ & $\mathrm{~N}$ \\
\hline Juraichhari & 2017,2018 & $0.27-0.41$ & $-0.19--0.14$ & $1.33-1.44$ & $8.28-12.57$ & $\mathrm{~N}$ \\
\hline Bilaichhari & 2017 & $0.41-0.48$ & $-0.22--0.19$ & $1.52-1.80$ & $8.28-12.57$ & W \\
\hline Kawkhali & 2017 & $0.27-0.41$ & $-0.19--0.14$ & $1.33-1.44$ & $12.57-16.85$ & SW \\
\hline
\end{tabular}

\section{Surface Geology}

Soils of Rangamati hills are Brown Hill soils occupy gentle to very steep slopes which have been developed over consolidated or unconsolidated rocks. Generally the subsoils are yellow to strong brown, friable, porous, sandy loam to sandy or silty clay loam, very strongly to extremely acidic (FAO 1986, 1988; UNDP 1986; Brammer 1996). Chattagram Hill Tracts region is dominated by two major Geological Group-Formations: Surma Group and Tipam Group. Surma Group has two Formations: Bhuban Formation (Sandstone dominates this formation) and Boka Bil Formation (generally shale and siltstone dominate the lower and the upper parts while in the middle part the sandstone percentage is much higher). Tipam Group is dominated by Tipam Sandstone Formation and the Girujan Clay (Chowdhury, Khan and Uddin 2015). The geological formation of hills in those areas, although not very young, is still in the process of degradation and reformation through weathering or other natural processes. Chandraghona and Kaptai area contains sedimentary rocks comprising dominantly of sandstone, shale and siltstone (Rahman, Mohiuddin and Hassan 1985). The detailed surface geology of Rangamati District is shows eight geological subclass (Figure 3).

Result shows that about 45\% landslide occurred in Boka Bil Formation, about 33\% in Dihing and Dupitila Formation Undivided and about 13\% in Tipam Sandstone areas. Dihing formation consists of medium-grained, occasionally pebbly sandstone and clayey sandstone with interbeds of mottled clay and has poorly consolidated rocks in most part. Dupi Tila Formation consists of fine to medium grained pebbly and cross-bedded sandstone with subordinate claystone and siltstone (Chowdhury, Khan and Uddin 2015). So it is evident that most of the landslide materials in Rangamati district are consist of clayey soil that has partly mixture of unconsolidated rock and sandstone. Due to the constituting material this kind of landslide can be defined as mudflow as we see this needs very low slope for triggering the landslide. 


\section{Distance from Fault Line}

In Rangamati District about 93\% landslides occurred within 11000 meters (11 Km) from the fault line (Table 4 and Figure 4). This indicates that like all over the world fault line plays a major role in occurring landslides in Rangamati District. Fault lines of Rangamati District are orientated southwest and north east direction (Figure 3). Due to this orientation land slide occurrence have shows strong correlation with the slope that have north, northeast, south and southwest aspect (Table 3 and 4 and Figure 6-A).

\section{NDVI}

State of vegetation can be a controlling factor for landslides (Tehranil and Hüsken 2019). This index output varies between -1.0 and 1.0 , mostly representing greenness, where any negative values are mainly generated from clouds, water, and snow, and values near zero are mainly generated from rock and bare soil. Very low values of NDVI ( 0.1 and below) correspond to barren areas of rock or sand. Moderate values $(0.2$ to 0.3$)$ represent shrub and grassland, while high values (0.6 to 0.8) indicate temperate and tropical rainforests (Ahmed et al. 2013). The NDVI of Rangamati District indicates that the landslide event occurred where the NDVI value is below 0.5 (Table 3 and Figure 5.A). It means that the landslide occurred area is covered by shrub or grass land or very little large trees.

\section{BSI}

Rapid urbanization and human development activities such as, building and road construction through deforestation and excavation of hill slopes have increased landslide in densely populated cities located in mountainous areas (Galli and Guzzeti 2007; Schuster and Highland 2007). The results of Bare soil shows positive DNs for built-up and bare areas, whereas the rest of land cover types had a value of zero or below (Bhatti and Tripathi 2014). Analysis reveals that maximum landslide events were occurred where the BSI value is medium (between -0.19 and -0.14 ) or high (between - 0.22 and -0.19 ) (Table 3 and Figure 5.B). These areas are covered with scattered vegetation or small tree. In the landslide event area soil is bare or there is little vegetation and has built up area.

\section{$\mathrm{NDCl}$}

Generally, the hills consist of unconsolidated sedimentary rocks such as sandstone, siltstone, shale and conglomerate. Soil of the Chattagram Hill Tracts are consists of alluvial, silty clay which is vulnerable to landslides (Islam 2018). At most areas, the soil consists of different layers of sand and clay/shale. Silty caly basically found in hill slope. Hill slope becomes unstable due to increased gravity load caused by heavy rainfall and other natural or anthropogenic actions on the slope (Alam et al. 2019) which makes it susceptible to massive soil erosion (Khan 2008). NDCl results reveal that most of the landslide occurred where medium clay content present on the surface. In this area the NDCl value ranges from 1.33-1.52 (Table 3 and Figure 5.C), which means landslide event occurred in the area where soil is composed with higher silt and clay content that can be easily saturated by rainwater. During heavy rainfall this saturated soil increases load and makes the mud eligible for flow. This mud load, by the pull of gravity, flows downward though it has not very steep slope (Figure 6.B and Table 3).

\section{Slope Angle}

Slope is the steepness of a surface, which is one of the indicators of stability of slopes (Clerici et al. 2006). Landslide occurred due to the downhill and outward movement of slope-forming materials under the influence of gravity (USGS 2004). Debris flows often begin as slides on steep hill slopes which transport material (Geertsema and Highland 2011). In Rangamati district almost all the event occurred where slope is below 16.85 degree (Table 3 and Figure 6.B). Excessive rainfall in Rangamati had saturated the soil resulting in increase of soil mass. The bedding of the soil formation is almost horizontal. Alternate layer of sand and very thin film of cements clay/shale layer. Rainwater seeps through the layers and creep effect reduces the bond between the sand and clay/shale layers (Alam et al. 2019). So behind the manmade cause rainfall and some geological causes also play role in triggering landslide in Rangamati. In Rangamati weak or sensitive weathered material composed with clay responsible for slide event that can be defined as mud flow in geomorphological terms.

\section{Slope Aspect}

Aspect is the orientation of slope, measured clockwise in degrees from 0 to 360 , where $0,90,180$ and 270 are north-facing, east-facing, south-facing, and westfacing, respectively. Aspect affects the exposure to sun-light, precipitation and wind thus affecting indirectly and other factors that contribute to landslides such as vegetation and, soil moisture and soil thickness (Clerici et al. 2006). In the Chattagram Hill Tracts the Upper Tertiary sandy-argillaceous sediments have been folded into a series of long submeridional (NNW-SSE) anticlines and synclines represented in the surface topography by elongated hill ranges and intervening valleys (Chowdhury 2015). Aspect of studied landlside events are SW, NW, NW, NE, SW, NE, S, NE, N, W, SW (Table 3 and Figure 6.B) which are highly expose to sun so that weathering occurred in this site rapidly. Rainfall also plays role in weathering and this site has get substantial rainfall during rainy season that loosen the soil and make it susceptible to landslide. The resulted aspects are also facing towards water body such as Kaptai Lake and Karnafuli River.

\section{Landslide Susceptible Area}

Occurrence of landslide in an area depends largely on complex interaction among a large number of factors (Dai et al. 2002). So the most exact method to landslide susceptibility is through field surveys (Catani et al. 2005; Nadim et al. 2006). But satellite remote sensing data can be a great information source for landslide susceptibility analysis. Data derived above are factors of landslide occurrence. By using frequency ratio method frequency ratio, relative frequency and predictability of each factor are identified. Frequency ratio indicates the correlation of landslide with the corresponding class. Results show that low slope has greater correlation with landslide occurrence (Figure 7 and Table 4). Northeast and southwest facing slopes also show same correlation (Figure 7 and Table 4). Greater correlation found for high to very high NDCl (Figure 7 and Table 4). Two major geological formations and low distance from fault has also grater correlation with landslide occurrence. 
Table 4

The correlation between occurring landslides and each conditioning factor using bi-variate model (frequency ratio method)

\begin{tabular}{|c|c|c|c|c|c|c|c|c|}
\hline Factor & Class & $\mathrm{CP}$ & $\% \mathrm{CP}$ & LO & $\%$ LO & FR & RF & PR \\
\hline \multirow[t]{6}{*}{ Geology } & Tipam Sandstone & 695700 & 11.05 & 2 & 13.33 & 1.21 & 0.10 & \multirow[t]{6}{*}{2.53} \\
\hline & Dihing and Dupitila Formation Undivided & 299865 & 4.76 & 5 & 33.33 & 7.00 & 0.60 & \\
\hline & Boka Bil Formation & 2703472 & 42.93 & 7 & 46.67 & 1.09 & 0.09 & \\
\hline & Dupitila Formation (Pleistocene and Pleicene) & 173701 & 2.76 & 1 & 6.67 & 2.42 & 0.21 & \\
\hline & Bhuban Formation & 1593601 & 25.31 & 0 & 0.00 & 0.00 & 0.00 & \\
\hline & Kaptai Lake & 738950 & 11.73 & 0 & 0.00 & 0.00 & 0.00 & \\
\hline \multirow[t]{3}{*}{ Distance from Fault Line (meter) } & $0-5,486.91$ & 4279837 & 70.09 & 5 & 33.33 & 0.48 & 0.11 & \multirow[t]{3}{*}{1.93} \\
\hline & $21,947.64-27,434.56$ & 34927 & 0.57 & 0 & 0.00 & 0.00 & 0.00 & \\
\hline & $27,434.56-32,921.47$ & 11903 & 0.19 & 0 & 0.00 & 0.00 & 0.00 & \\
\hline \multirow[t]{5}{*}{ Slope } & $0-3.71$ & 1283406 & 19.85 & 0 & 0.00 & 0.00 & 0.00 & \multirow[t]{5}{*}{1} \\
\hline & $3.71-8.28$ & 1439114 & 22.25 & 4 & 26.67 & 1.20 & 0.16 & \\
\hline & $8.28-12.57$ & 1205855 & 18.65 & 5 & 33.33 & 1.79 & 0.24 & \\
\hline & $12.57-16.85$ & 991836 & 15.34 & 3 & 20.00 & 1.30 & 0.17 & \\
\hline & $16.85-21.14$ & 702293 & 10.86 & 1 & 6.67 & 0.61 & 0.08 & \\
\hline \multirow{9}{*}{ Aspect } & North & 347585 & 5.38 & 3 & 20.00 & 3.72 & 0.31 & \multirow{9}{*}{1.30} \\
\hline & Northeast & 768910 & 11.89 & 3 & 20.00 & 1.68 & 0.14 & \\
\hline & East & 849812 & 13.14 & 0 & 0.00 & 0.00 & 0.00 & \\
\hline & Southeast & 723460 & 11.19 & 0 & 0.00 & 0.00 & 0.00 & \\
\hline & South & 712398 & 11.02 & 1 & 6.67 & 0.61 & 0.05 & \\
\hline & Southwest & 866314 & 13.40 & 3 & 20.00 & 1.49 & 0.12 & \\
\hline & West & 862677 & 13.34 & 1 & 6.67 & 0.50 & 0.04 & \\
\hline & Northwest & 669773 & 10.36 & 2 & 13.33 & 1.29 & 0.11 & \\
\hline & North & 300523 & 4.65 & 2 & 13.33 & 2.87 & 0.24 & \\
\hline \multirow[t]{5}{*}{ BSI } & $-0.39--0.22$ & 1743836 & 26.97 & 1 & 6.67 & 0.25 & 0.05 & \multirow[t]{5}{*}{3.66} \\
\hline & $-0.22--0.19$ & 2840443 & 43.92 & 3 & 20.00 & 0.46 & 0.09 & \\
\hline & $-0.19--0.14$ & 1070828 & 16.56 & 11 & 73.33 & 4.43 & 0.86 & \\
\hline & $-0.14--0.08$ & 727687 & 11.25 & 0 & 0.00 & 0.00 & 0.00 & \\
\hline & $-0.08-0.14$ & 83793 & 1.30 & 0 & 0.00 & 0.00 & 0.00 & \\
\hline NDVI & $-0.29-0.07$ & 546938 & 8.46 & 0 & 0.00 & 0.00 & 0.00 & 3.51 \\
\hline
\end{tabular}




\begin{tabular}{|c|c|c|c|c|c|c|c|c|}
\hline Factor & Class & $\mathrm{CP}$ & $\% \mathrm{CP}$ & LO & $\%$ LO & FR & RF & PR \\
\hline & $0.41-0.48$ & 2441392 & 37.75 & 5 & 33.33 & 0.88 & 0.14 & \\
\hline & $0.48-0.65$ & 2471644 & 38.22 & 1 & 6.67 & 0.17 & 0.03 & \\
\hline \multirow[t]{4}{*}{$\mathrm{NDCl}$} & $0.534-1.14$ & 599926 & 9.28 & 0 & 0.00 & 0.00 & 0.00 & \multirow[t]{4}{*}{2.78} \\
\hline & $1.33-1.44$ & 1354756 & 20.95 & 8 & 53.33 & 2.55 & 0.66 & \\
\hline & $1.44-1.52$ & 2373567 & 36.71 & 6 & 40.00 & 1.09 & 0.28 & \\
\hline & $1.52-1.80$ & 1723260 & 26.65 & 1 & 6.67 & 0.25 & 0.06 & \\
\hline
\end{tabular}

According to this result weighted map of landslide susceptility of Rangamati district shows medium to high landslide susceptible areas are located near Kaptai Lake and Karnafuli river and in the slope of hills (Fig. 7). These areas are adjacent to fault line and have similar orientation with the slope aspect and have a low slope. There are many areas that are moderately susceptible to landslide during heavy rainfall.

\section{Conclusion}

Landslide vulnerability is an important issue for people living in the hilly areas of Rangamati. The major impacts of landslide on the local communities were destruction of settlement, economic loss, loss of lives and environmental problems (Alam, 2019). This study uses a popular Bi-variate statistical model (frequency ratio) to assess landslide susceptible areas of Rangamati. Satellite images derived landslide triggering factors and existing geological data gives a clear idea about previously occurred landslide event to predict the future landslide prone area using the model. This model also predicts the correlation between the landslide event and the triggering factors. Landslide of Rangamati has a strong correlation with surface lithology and fault line. Another major correlation is seen with bare soil that has low slope and has high clay content. Almost all the landslide occurred in Tipam, Dupitila and Dihing group formation that are dominated by clay and unconsolidated rock and sandstone. Adjacent areas of Kaptai Lake are dominated by that type of group formation. So heavy rainfall in the region can easily saturated the soil to produce mud and as the load of muddy soil increases it can travel with a very low slope. The areas where human settlements are situated in gentle slope side of the hills are more vulnerable because heavy rainfall can easily saturate the soil and the extra stress added by settlement triggers the mud to flow downward. The soils that constituent of Tipam, Dupitila and Dihing group formation are more susceptible to landslide than other group formation. Low slope near water body are also vulnerable because they are more erosive prone than other. Further investigation, detailed soil survey, lab analysis of landslide flow material of the region can help to identify vulnerable area more accurately.

\section{List Of Abbreviations}

SRTM = Shuttle Radar Topography Mission

DEM = Digital Elevation Model

NDVI = Normalized Difference Vegetation Index

BSI = Bare Soil Index

$\mathrm{NDCl}=$ Normalized Difference Clay Index

GIS = Geographic Information System

LSM = Landslide Susceptibility Map

GSB = Geological Survey of Bangladesh

\section{Declarations}

\section{Availability of data and materials}

The datasets used and/or analysed during the current study are available from the corresponding author on reasonable request.

\section{Competing interests}

The authors declare that they have no competing interests

\section{Funding}

Not applicable 


\section{Authors' contributions}

Bibi Hafsa develops the idea of the research and read and corrected the manuscript for finalization.

Md. Sharafat Chowdhury analyzes the data, interprets them and prepared the manuscript.

Md. Naimur Tian collected the historical land slide data and makes them useable in GIS format.

\section{Acknowledgements}

Not applicable.

\section{Significance of the manuscript}

“Landslide Susceptibility Assessment Based on Geological Data and Remote Sensing Processed Data Using Bi-variate Statistical Model and GIS: A Case Study on Rangamati District, Bangladesh" is a case study article. In this research authors used a Bivariate Statistical model and GIS method to predict landslide susceptible areas of Rangamati District, Bangladesh. There are very few work conducting on this issue for this region. This article will help the reader to understand the major landslide influencing factors of the region and will introduce with GIS application of Bivariate model for prediction and correlation analysis. This also helps policymaker to understand the landslide prone areas of the district.

\section{References}

1. Ahmed B, Rahman MS, Rahman S, Huq FF, Ara S (2014) Landslide Inventory Report of Chittagong Metropolitan Area, Bangladesh. BUET Japan Institute of Disaster Prevention and Urban Safety (BUET-JIDPUS). Dhaka-1000, Bangladesh. p-125.

2. Akgun A, Dag S, Bulut F (2008) Landslide susceptibility mapping for a landslide-prone area (Findikli, NE of Turkey) by likelihood-frequency ratio and weighted linear combination models. Environ Geol 54:1127-1143.

3. Alam EM, Chowdhury MAT, Akbar MT (2005) Aspects of social environmental problems resulting from hill cutting in the city of Chittagong, Bangladesh: local people's perspectives. PJSS 3 (8):1048-1052.

4. Alam TA, Kamal A, Barua G, Omi FR (2019) A Study of The Recent Landslide in Rangamati Region: Causes, Impacts and Existing Slope Protection Measures. Proceedings on International Conference on Disaster Risk Management, Dhaka, Bangladesh.

5. Apip, Takara K, Yamashiki Y, Sassa K, Ibrahim AB, Fukuoka H (2010) A distributed hydrological-geotechnical model using satellite-derived rainfall estimates for shallow landslide prediction system at a catchment scale. Landslides 7:237-258.

6. Bangladesh: Rain triggers landslides and leaves 107 dead. BBC News. 13 June 2017.

7. BBS (Bangladesh Bureau of Statistics) (2001) Bangladesh Population Census.

8. BBS (2009a) Compendium of environment statistics of Bangladesh. Bangladesh Bureau of Statistics (BBS), Statistics Division, Ministry of Planning, Government of Bangladesh (GoB), Dhaka.

9. BBS (2009b) Statistical yearbook of Bangladesh. Bangladesh Bureau of Statistics (BBS), Statistics Division, Ministry of Planning, Government of Bangsladesh (GoB), Dhaka.

10. Begum A, Islam MS, Hasan MM (2020) Landslide susceptibility mapping using GIS and Remote Sensing: A case study of the RangamatiDistrict, Bangladesh. PREPRINT (Version 1) available at Research Square [+https://doi.org/10.21203/rs.3.rs-23600/v1+]. 10.21203/rs.3.rs-23600/v1.

11. Bhatti SS, Tripathi NK (2014) Built-up area extraction using Landsat 8 OLI imagery. GISci Remote Sens 51(4):445-467.

12. Bonham-Carter GF (2014) Geographic Information Systems for Geoscientists: Modelling with GIS. Elsevier: Amsterdam, The Netherlands 13.

13. Brammer $\mathrm{H}$ (1989) Monitoring the evidence of the greenhouse effects and its impacts on Bangladesh, Dhaka, in H. Moudud (ed.). Proceedings of the Conference on the Greenhouse Effects and Coastal Area of Bangladesh, Dhaka.

14. Brammer H 1(996) The Geography of the Soils of Bangladesh. University Press Ltd., Dhaka.

15. Catani F, Casagli N, Ermini L, Righini G, Menduni G (2005) Landslide hazard and risk mapping at catchment scale in the Arno River basin. Landslide 2(4):329-342. 10.1007/s10346-005-0021-0.

16. Chapagai D (2011) Landslide problem of South Asia and vis-a-vis Global Scenario. SAARC training program on landslide risk management in South Asia, SAARC Disaster Management Centre (SDMC), New Delhi.

17. ChenWC, Chen H, We LW, Lin GW, Lida T, Yamada R (2017) Evaluating the susceptibility of landslide landforms in Japan using slope stability analysis: A case study of the 2016 Kumamoto earthquake. Landslides 14:1793-1801. [CrossRef]

18. Clark RN, King TVV, Klejwa M, Swayze GA (1990) High Spectral Resolution Reflectance Spectroscopy of Minerals. J Geophys Res 95(B8):12653-12680.

19. Clark RN, Swayze GA, Wise R, Livo KE, Hoefen TM, Kokaly RF, Sutley SJ (2003) USGS Digital Spectral Library splib05a. USGS Open File Report, 03-395.

20. Cruden DM (1991) A simple definition of landslide. IAEG 43(1):27-29.

21. CSRRD (Cultural survey report of Rangamati District) (2007).

22. CSRRURD (Cultural survey report of upazilas of Rangamati District) (2007).

23. Dai EC, Lee CF, Nagi YY (2002) Landslide risk assessment and management: An overview. Eng Geol 64:65-87.

24. Denissen AK ( 2017) Climate Change \& its Impacts on Bangladesh, Retrieved from NCDO: https://www.ncdo.nl/artikel/climate-change-its-impactsbangladesh 
25. DMB (2010) Standing Orders on Disaster. Ministry of Food and Disaster Management, Disaster Management \& Relief Division, Disaster Management Bureau. Dhaka, Bangladesh, April 2010.

26. FAO (1986) Classification of the Soils of Bangladesh.

27. FAO (1988) Land resources appraisal of Bangladesh for agricultural development. 2, Rome.

28. Farahmand A, AghaKouchak A (2013) A satellite-based global landslide model. Nat Hazard Earth Sys 13:1259-1267. 10.5194/nhess-13-1259-2013.

29. Galli M, Guzzetti F (2007) Landslide vulnerability criteria: A case study from Umbria, central Italy. Environ Manage 40:649-664.

30. Geertsema M, Highland LM (2011) Landslides: human health effects. [cited 2018 Dec 22]. Available from:

https://www.researchgate.net/publication/233906018_Landslides_Human_Health_Effects. 10.1016/B978-0-444-52272-6.00550-X.

31. GSB (Geological Survey of Bangladesh) (1990) Geological map of Bangladesh. available at: https://pubs.usgs.gov/of/1997/ofr-97-470/OF97470H/ofr97470H_geo.pdf

32. Haque DME, Sifa S, Mahmud T, Tarin MA (2018) Landslide Susceptibility Assessment for Rangamati District in Bangladesh Based on Satellite Image Processing and Bi-variate Statistical Modeling. Bangladesh Journal of Physics 23 \& 24:93-106. 10.13140/RG.2.2.13238.19522.

33. Highland LM, Bobrowsky P (2008) The Landslide Handbook-A Guide to Understanding Landslides. Virginia: U.S. Geological Survey Circular 1325.

34. Hong Y, Adler R, Huffman G (2006) Evaluation of the potential of NASA multi-satellite precipitation analysis in global landslide hazard assessment. Geophys Res Lett 33. L22402, 10.1029/2006GL028010.

35. Imbrone A, Melenti C, Gorgan D (2007) Mineral Explorations by Landsat Image Ratios. Conference Paper, D0I: 10.1109/SYNASC.2007.52. Source: DBLP

36. Islam MS (2018) Effect, Causes, and Possible Measure of Landslide in Bangladesh (Chittagong). Eng Sci 3(4):58-63.

37. Kafy A, Hasan MM, Ferdous L, Ali MR, Uddin MS (2019) Application of Artificial Hierarchy Process for Landslide Susceptibility Modeling in Rangamati Municipality Area, Bangladesh. Proceedings, International Conference on Disaster Risk Management, Dhaka, Bangladesh, January 12-14, 2019. Available from:

https://www.researchgate.net/publication/331008711_Application_of_Artificial_Hierarchy_Process_for_Landslide_Susceptibility_Modelling_in_Rangamati. [accessed January 17 2020].

38. Khan IS (2008) Hill cutting in Chittagong City Corporation area: its causes and the consequences. PhD Dissertation. Khulna University, Bangladesh.

39. Khatun M, Hossain S, Sayem HM, Patwary MA, Karim M (2018) LANDSLIDE SUSCEPTIBILITY MAPPING OF SOUTH-EASTERN RANGAMATI DISTRICT, BANGLADESH. Conference: GSA Annual Meeting in Indianapolis, Indiana, USA - 2018. 10.1130/abs/2018AM-316135.

40. Landslides: human health effects; [cited 2018 Dec 22]. Available from: https://www.researchgate.net/publication/ 233906018_Landslides_Human_Health_Effects

41. Lee S, Talib JA (2005) Probabilistic landslide susceptibility and factor effect analysis. Environ Geol 47:982-990. 10.1007/s00254-005-1228-z.

42. Marrapu BM, Jakka RS (2014) Landslide Hazard Zonation Methods: A Critical Review. Int J Civ Eng 5(3):215-220.

43. Nadim F, Kjekstad O, Peduzzi PC, Herold, Jaedicke C (2006) Global landslide and avalanche hotspots. J Landslides 3(2):159-173. 10.1007/s10346-0060036-1.

44. Nohani E, Moharrami M, Sharafi S, Khosravi K, Pradhan B, Pham BT, Lee S, Melesse MA (2019) Landslide Susceptibility Mapping Using Different GISBased Bivariate Models. Water 11(1402):1-22. 10.3390/w11071402.

45. Rahman QMA, Mohiuddin MZ Hassan M (1985) Geology of the Chandraghona-Kaptai area, Rangamati District, Bangladesh, In Records of Geological Survey of Bangladesh, Dhaka, Availabe at: http://gsb.portal.gov.bd/sites/default/files/files/gsb.portal.gov.bd/publications/29f1308f_604d_4b7b_ 8aab_6f29aef6c93b/Vol\%203,\%20Part\%203\%20-\%20Front\%20Page\%20and\%20Abstract.pdf

46. Sarwar GM (2008) Landslide Tragedy of Bangladesh. Tokyo, Japan: The First World Landslide Forum, United Nations University (UNU).

47. Spiker E, Gori P (2003) National landslide hazards mitigation strategy - A framework for loss reduction. US Geological Survey Circulars $1244: 1-64$.

48. Tarolli P, Tarboton DG (2006) A new method for determination of most likely landslide initiation points and the evaluation of digital terrain model scale in terrain stability mapping. Hydrol Earth Syst Sci 10:663-677.

49. Tehrani1 FS, Hüsken L (2019) Landslide susceptibility mapping of refugee camps in Bangladesh. 2nd International Conference on Natural Hazards \& Infrastructure, 23-26 June, 2019, Chania, Greece.

50. The Financial Express. 14 June 2017. Bangladesh landslide toll reaches 152. (Bangladesh). Dhaka.

51. Uddin T, Islam MT, Gosney JE (2019) 2017 Bangladesh landslides: physical rehabilitation perspective, Disability and Rehabilitation, Disability and Rehabilitation. Taylor \& Francis 1464-5165. (Online) Journal. https://doi.org/10.1080/09638288.2019.1620879.

52. UNDP (1986) Classification of the soils of Bangladesh.

53. USGS (2004) Landslide types and processes. Fact Sheet 2004-3072. U.S. Department of the Interior, U.S. Geological Survey. July 2004. [cited 2019 May 20]. Available from: https://pubs. usgs.gov/fs/2004/3072/fs-2004-3072.html.

54. USGS (2006) Landslide hazard Program, Tech. rep., United States Geological Survey, 2006.

\section{Figures}




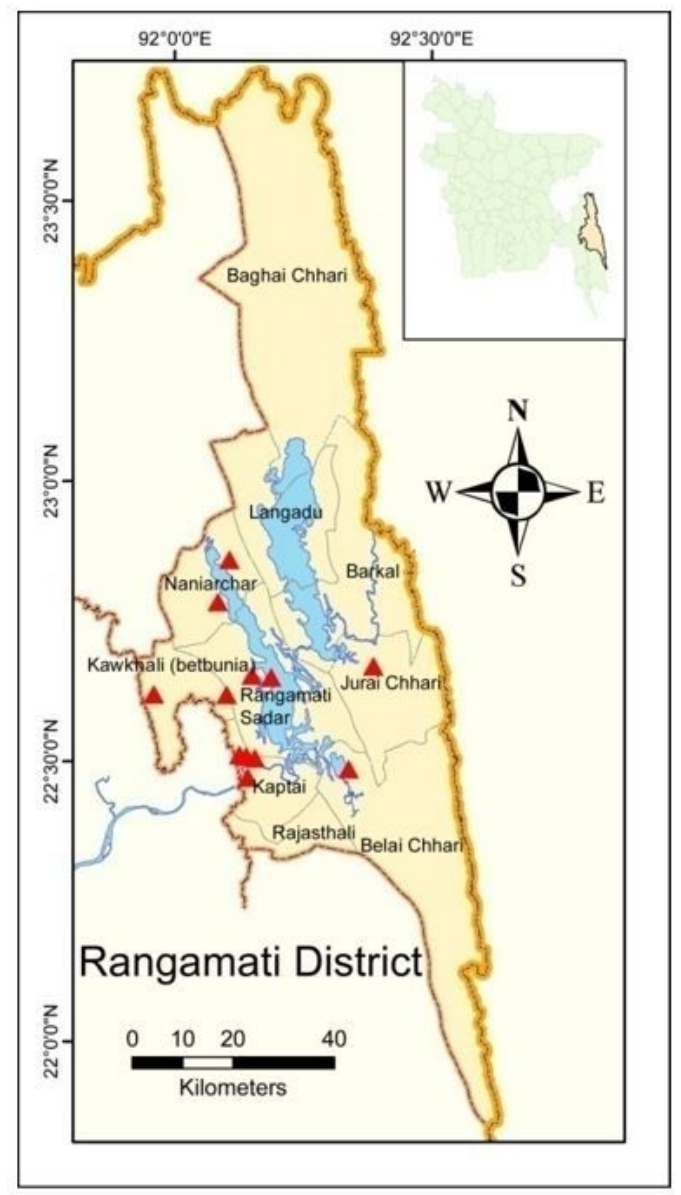

Figure 1

Study Area (red triangle = location of landslide occurrence)

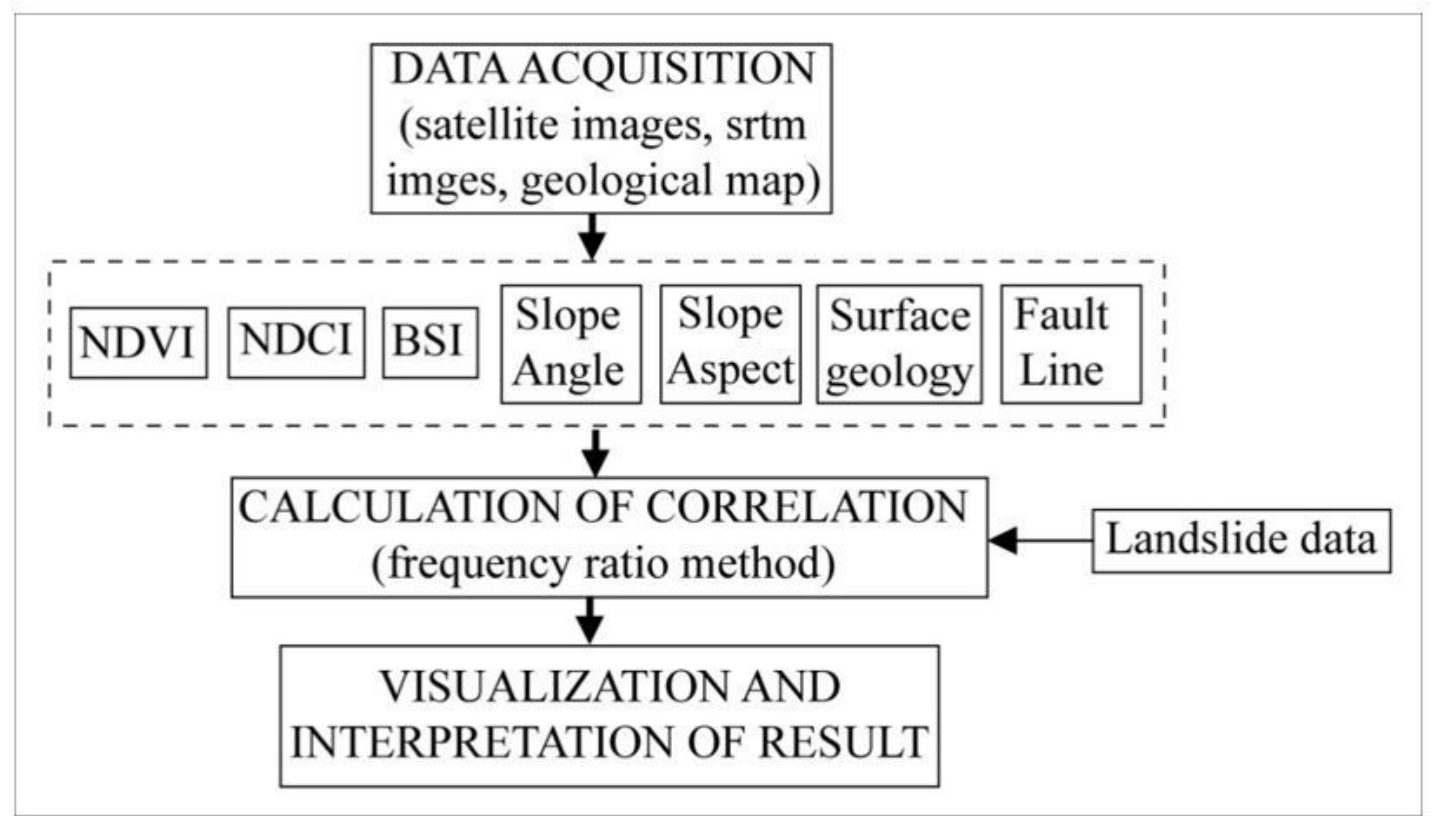

Figure 2

Methodological Summary 


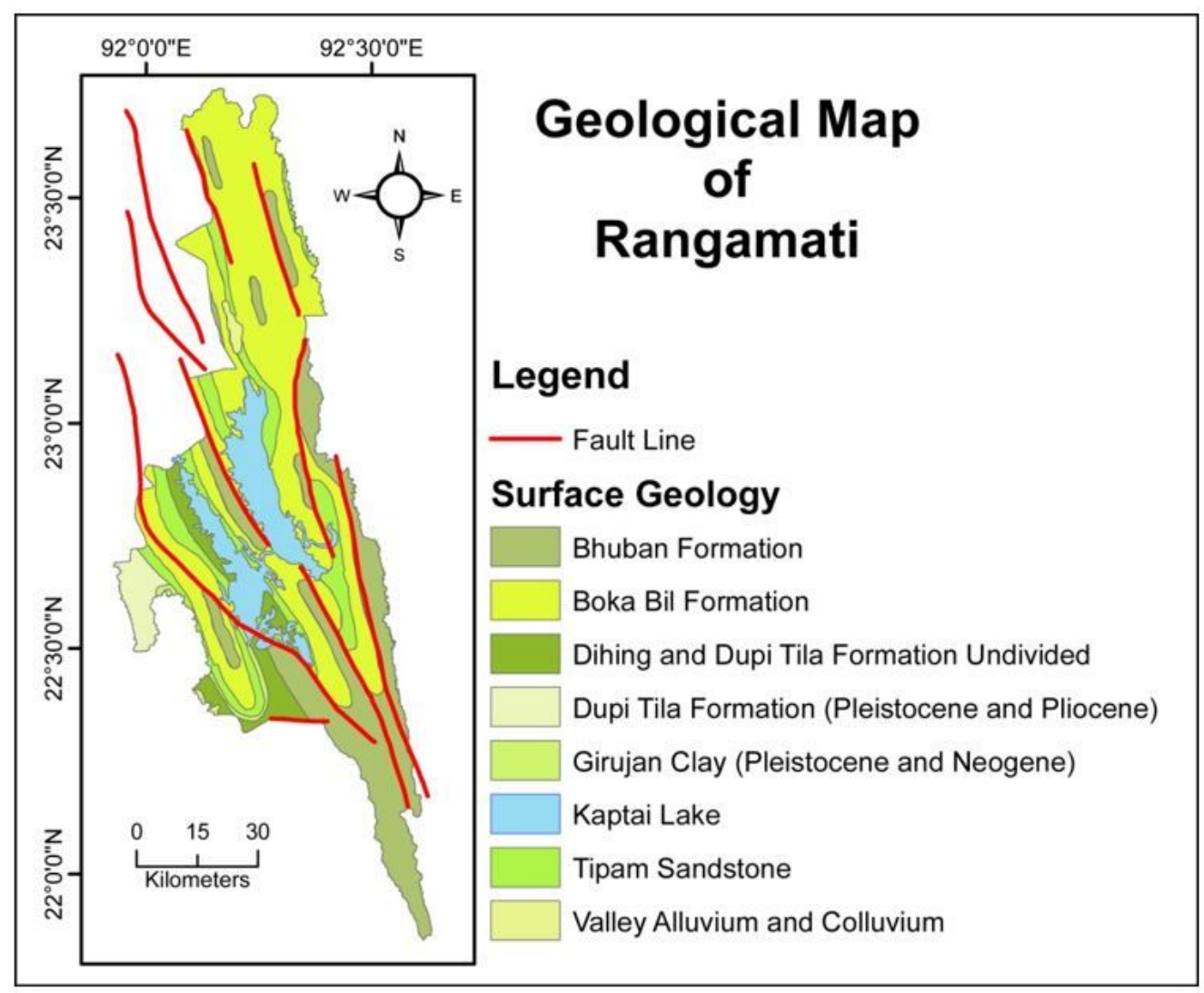

Figure 3

Geology of Rangamati District (Adopted from GSB)

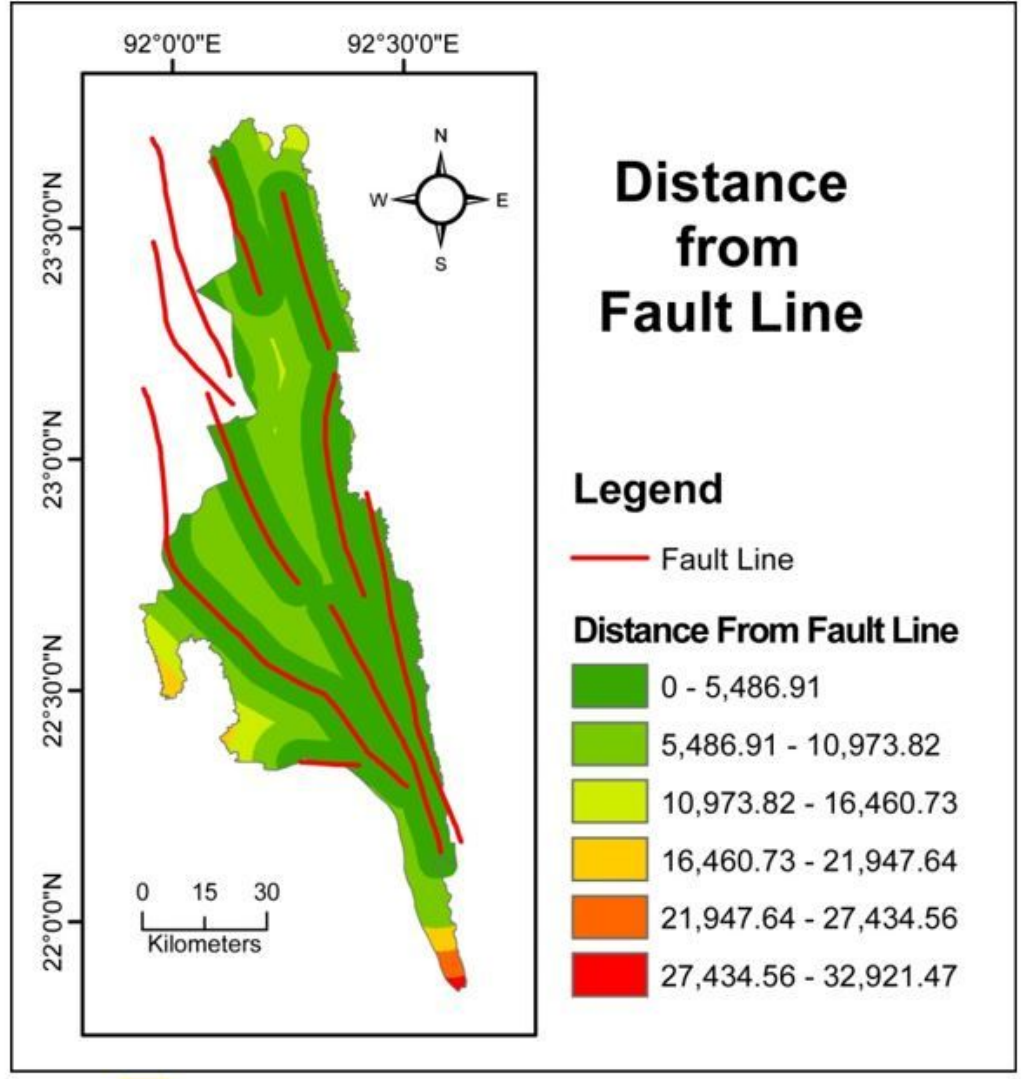

Figure 4 


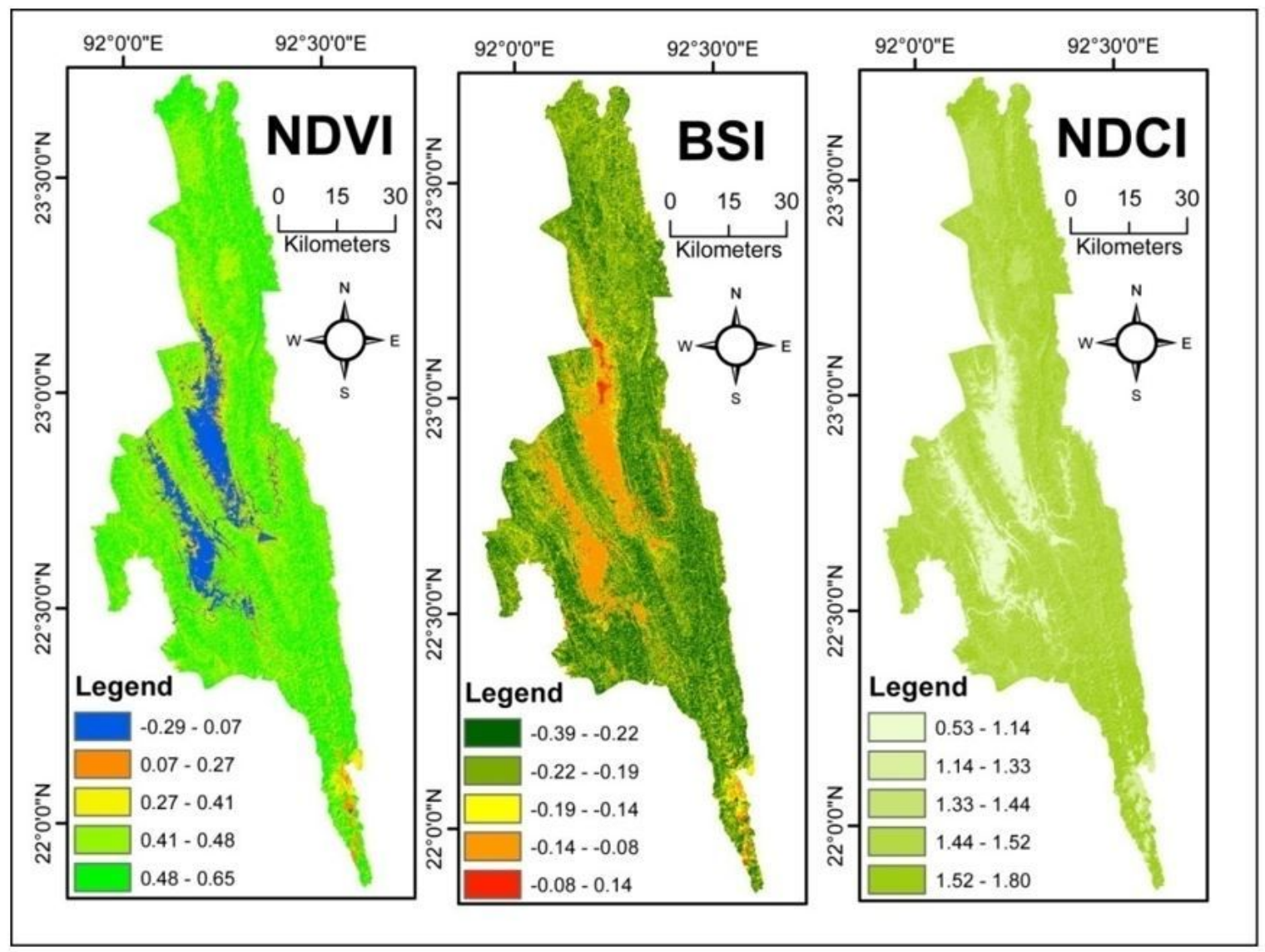

Figure 5

A) NDVI, B) BSI and C) $\mathrm{NDCl}$ of the study area 


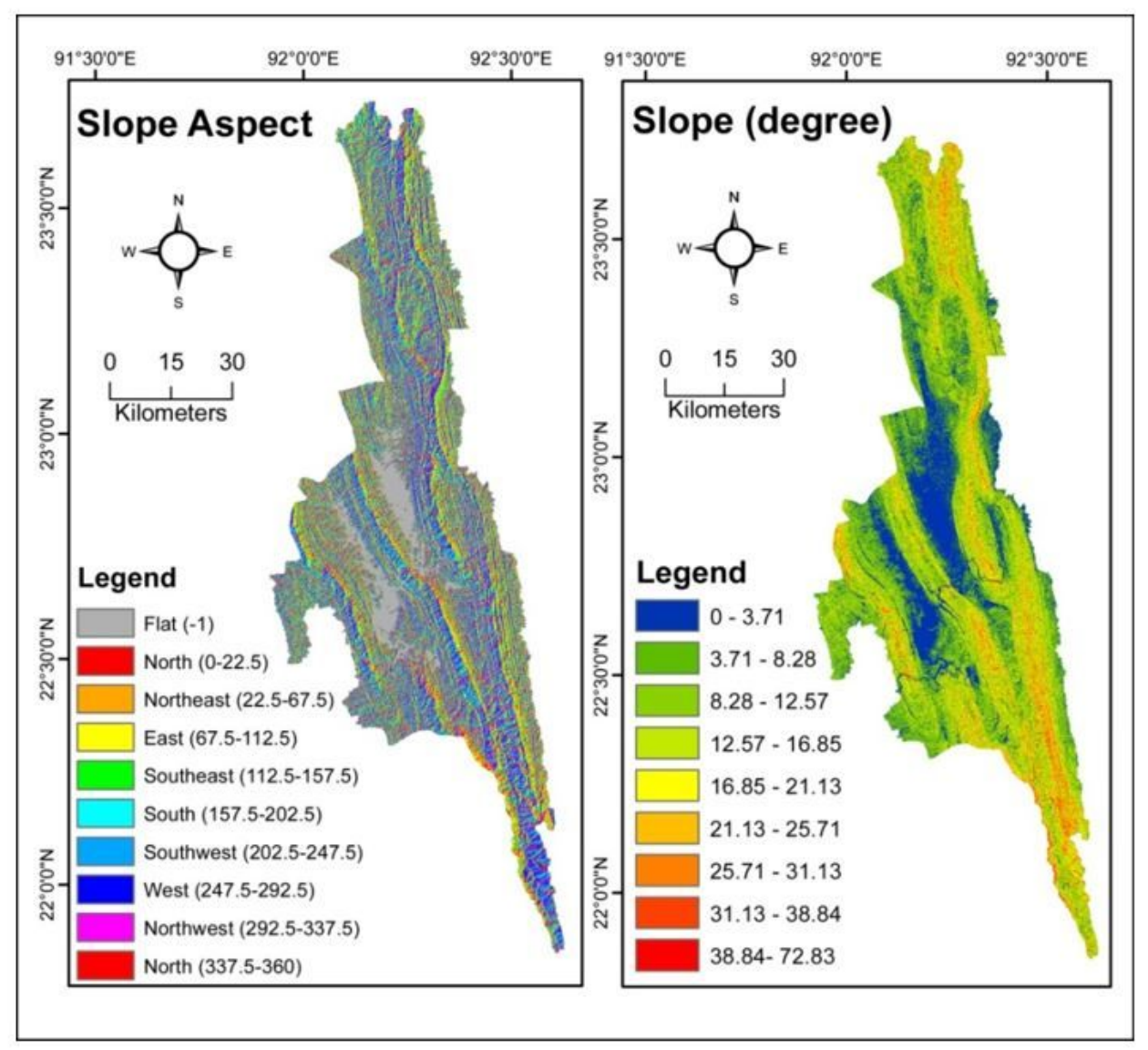

Figure 6

A) Slope Aspect and B) Slope Angle (degree) 


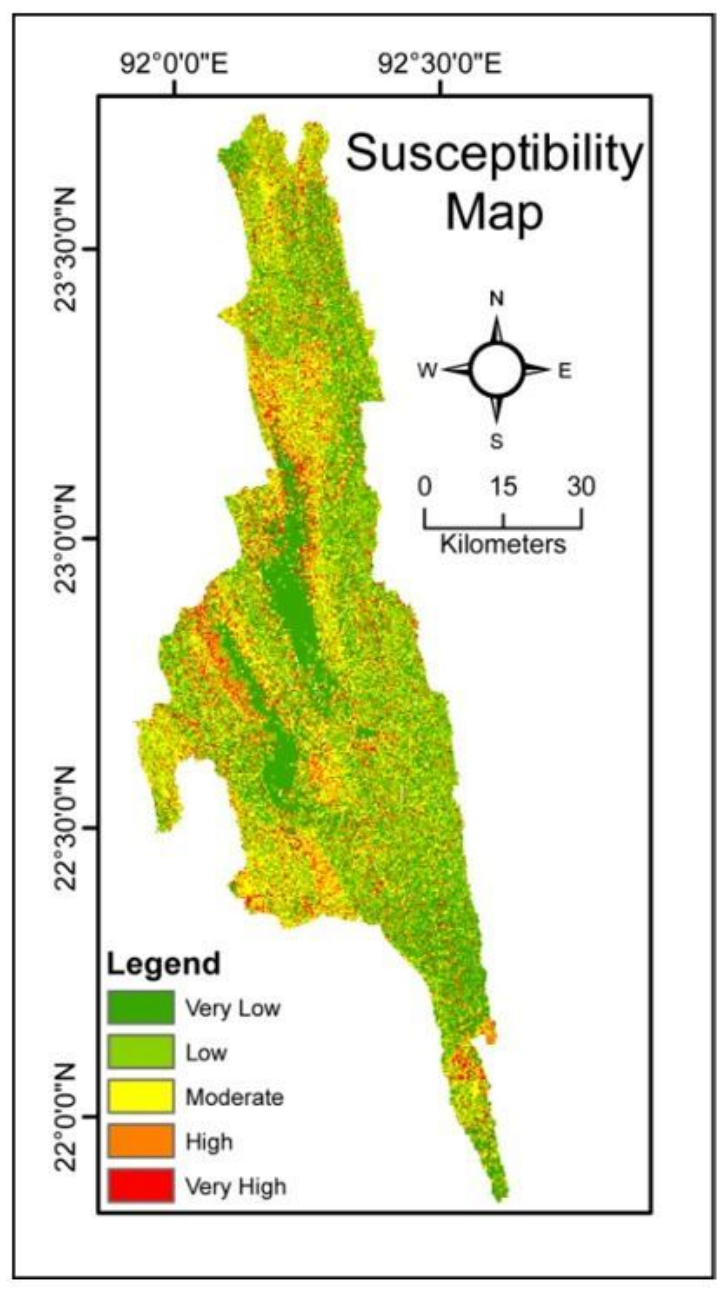

Figure 7

Landslide susceptibility map of Rangamati District 